\title{
Studying on Construction Programs of the Platform of Primary Products Marketing
}

\author{
Gang $\mathrm{Lu}^{1}$, Peng $\mathrm{Lu}^{2}$, and Cuie $\mathrm{Liu}^{3}$ \\ ${ }^{1,3}$ School of Management and Engineering, \\ Shijiazhuang University of Economics, \\ Shijiazhuang, Hebei, China \\ ${ }^{2}$ Tourism Department, Hebei Normal University, \\ Shijiazhuang, Hebei, China \\ 1031@163.com, lpzzllh@126.com, \\ liucuie@sjzue.edu.cn
}

\begin{abstract}
As a kind of advanced productive forces, the advantage and potential of E-commerce could not be ignored for upgrading the industrialization degree of agriculture, adjusting the agricultura structure, reducing the transaction cost of agricultural products and enlarging the market sale range and channels of agricultural products. This paper analyzes the present status and problems of application of Chinese agricultural E-commerce, points out that constructing primary products marketing platform is the first step to develop agricultural E-commerce. Combining with the situation and characteristics of Chinese agriculture, it gives out constructing programs and the frameworks of Chinese primary products marketing platform. Anlysize these programs and proposed Implementation Strategy from the Adaptive Point of View.
\end{abstract}

Keywords: Agriculture; Electronic Commerce Platform; Primary products Marketing; Implementation Strategy.

With the rapid development of modern information technology, the information technology is applied more and more widely in the agriculture field and becomes an important measure on promoting development of agricultural science and technology and agricultural and rural economy. At present, series of websites related with agriculture and agricultural informatization platforms have been initially formed and play an important role in transforming traditional agriculture and developing modern agriculture.

\section{General Introduction to Rural Informatization and Agricultural Electronic Commerce Development in China}

The gap between urban and rural informatization is great in China, so is the gap between urban and rural utilization ratio. According to a survey by CNNIC in July 2006, the netizens who engage in the occupation related with agriculture account for only $1.29 \%$ of the total. Most netizens are agriculture managers and technicians and 
are concentrated in the developed regions like Beijing, Shanghai, Guangdong, Zhejiang and Jiangsu, and farmers surfing on Internet are few, which indicates that farmers and farm owners haven't attached importance to the agricultural electronic commerce, so its regional distribution is imbalanced and its popularization and application is at low level. The Survey Report on Rural Internet Development in China 2009 by CNNIC shows that by the end of 2009, the number of urban netizens has reached 277.19 million, much higher than that of netizens in rural areas with greater population. Fortunately, compared with the situation in the previous two years, the growth rate of number of rural netizens is great. According to statistics, the scale of rural netizens in China increased very quickly and by the end of December 2009, their number has reached 106.81 million, with an annual growth rate of $26.3 \%$.

China is a large agricultural country, with the popularization of Internet in Agriculture and rural area, the development of agricultural electronic commerce shows vigorous trend: the application of electronic commerce in agriculture becomes wide, the agricultural information networks are established in many provinces, with some large online markets emerging. The varieties operated online change from food and fertilizer previously playing a key role to subsidiary food, poultry, pesticide, special and local product, flowers, gardens, aquatic products, tea and fresh fruits which are all operated online, establishing platforms for rural economic information to spread to villages and households. According to statistics by CNNIC, by the end of 2009, there have been over 10000 websites related with agriculture, which release a lot of agricultural supply and demand information for vegetables, melons and fruits, tree seedlings, livestock and poultry and raising and relevant economic information and investment invitation information, playing an important role for promoting agricultural products, improving agricultural efficiency and increasing farmers' income. The websites with great influence are China Agricultural Technology Information Net(www.caas.net), China Agricultural Information Net (www.agri.sov.cn), China National Seed Group Co., Ltd. (www.chinaseeds.com.cn). The rural supply and demand information service system, national broadcast system for rural supply and demand information currently has 35000 registered members and release 8000 pieces of information with over 250 thousand pieces of content retrieval. All this indicates that the agricultural electronic commerce in China enters stage of rapid development.

\section{Problems of Electronic Commerce Platform for Agricultural Products in China}

The factors such as low computer penetration and inadequate information, lead to the situation of long marketing link, high transaction cost and serious separation of supply and demand chains for agricultural products in China. So the issues of agriculture, farmer and rural area like difficulty for farmers' income increase, heavy agricultural burden and various problems in rural area still hinder the development of rural areas in China. In addition, the individual farmer's and small-scale agricultural organization's poor ability for collecting, seizing and analyzing market information seriously restricts the development of agricultural electronic commerce. In summary, the main factors restricting the development of electronic commerce platform for agricultural products are as follows: 


\subsection{Few Information Sources and Updating Not in Time}

As for agricultural electronic commerce platform, it is very important to provide supply and demand information, price information and agricultural materials. Therefore, in-time updating of information and broad information sources plays an important role in the platform, or the online effective resources will be deficient.

\subsection{Imperfect Transaction Functions and Safety Hazard}

Most platforms don't have online order transaction system and can't realize real function of electronic commerce. Moreover, the platform is lack of safety mechanism. It only provides information service functions and is lack of identification and supervision and management for membership. Also it is not definite for member system and classification for member levels, bringing safety hazard for transaction.

\subsection{Unable to Contact with Chains of Agricultural Production Closely}

Most agricultural product platforms pay too much attention to the finish products, the postproduction chain, but can't contact with the pre-production or mid-production chains. Therefore, the following situation occurs: the blind pre-production plan causes the imbalance of supply and sales which will lead to the price fluctuation and further affect social stability and farmer's enthusiasm; the lack of supplying the information for pesticide, seeds and fertilizer together with the limited ability of farmers to process information decrease the effective utilization of information.

\subsection{Characteristics of Agricultural Products}

Many agricultural products have the characteristics of seasonality and difficulty for storage, so it is difficult to keep them fresh, transport them and conduct post processing for them, which increases the difficulty for their logistics chains, compared to the industrial products, further increases the difficulty to carry out agricultural electronic commerce and restricts the development of electronic commerce platform for agricultural products.

\subsection{Poor Electronic Commerce Consciousness}

The core of information technology is information rather than technology, while the core of electronic commerce is commerce rather than electronization. The internet is only one new channel for enterprises to expand business. Some enterprises, during the implementation of electronic commerce, excessively pursuit the advanced hardware equipment and immature high technology and ignore the optimization and integration of internal and external information resources of the enterprises. So it is difficult for them to realize high-quality, high-efficiency and high-benefit commercial activities.

\subsection{Unsound Electronic Commerce Environment}

At present, the imperfection of the standards and regulations of bank, information industry, tax, customs, finance and laws, related with electronic commerce in China, 
and poor standardization and organization of agricultural product markets affect farmers' trust on electronic commerce. In addition, the low level of standardization for agricultural products in China and difficulty to unify the standards for many agricultural products, to some extent, limit the development of electronic commerce for agricultural products.

In general, the agriculture in China develops backward currently. However, the annual national policy and support for agriculture is constantly strengthened. Thus the infrastructure construction for agricultural informatization, the farmers' cultural quality and application level of information technology, management concept of agricultural enterprises and the operation environment for electronic commerce will be improved rapidly and the network operation cost will be reduced quickly. Therefore, it is urgent to quickly establish application platforms for agricultural electronic commerce, guide the agricultural enterprises to transform operation concept and management mode to implement electronic commerce as soon as possible.

\section{Development Strategy of the Electronic Commerce Platform for Chinese Agricultural Product}

The following development strategies are applied focused on the current problems existing in the electronic commerce platform for Chinese agricultural products:

\subsection{Perfecting the Information Network System and Strengthening the Channel of Acquiring the Information}

Once the wide and complete social information network system is established, the effective information in a wide range can be acquired on time, thus forming the dynamic and intensive social information network. In such a way of acquiring the effective information, the correct and latest information can be provided to the platform member, not only improving the credit from the members but also founding the base of the network service. And also, the complete information channel is the guarantee to provide the correct information for tendering the better services to the peasant households and enterprise. Therefore the platform for agricultural products can develop the cooperation relationship with the various important agricultural information networks and agricultural media to acquire more complete and valuable information.

\subsection{Perfecting the Function of Online Transaction on the Third-Party Platform}

The third-party electronic commerce platform is suitable for the medium- and smallsize agricultural operation units. Based on the public platform provided by the thirdparty platform, these units can carry out the electronic commerce activities, not only implementing the electronic commerce, but also participating in the third-party commerce platform with only a relatively small cost, so they can enjoy the professional information service and value-added service and have more chances of developing the market. Meanwhile, the third-party electronic supplier shall, with using the operating mechanism of the commercial Web site and under the framework of the electronic trade, establish the open inter-trade electronic commerce system used really aimed to provide the whole commerce course. 


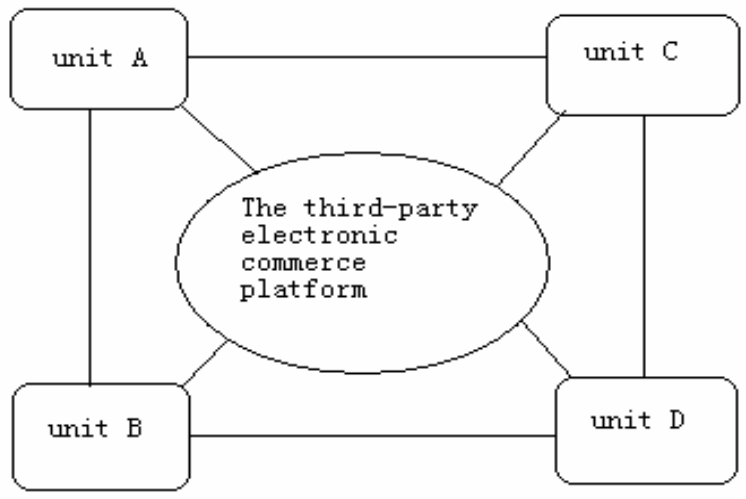

Fig. 1. The third-party electronic commerce platform framework

The third-party commerce, over several years' exploration and operation, has become mature and its mode is a very effective method of accelerating the development of the electronic commerce of the Chinese agriculture. Under the support form the society and the government, the third-party agricultural electronic commerce platform shall cover the perimeter zone and surrounding provinces with the region as the center, to provide the better and more effective service support to more agricultural production operation units.

The third-party electronic commerce platform not only requires the functions of releasing the basic demand information and the product price information, but also requires a further improvement in the aspects of safety, payment and customer relationship. So far, many electronic commerce platform involved in the agriculture is just for the visitors browsing the statistic information, and that is far from the requirement, and it should be equipped with the functions as follows: releasing the product information, checking the production information quickly, online customer consulting, querying the order, commercial negotiation on line, online transaction and payment, logistics distribution and delivery, customer's feed back, customer service, investment opportunities, product information, solutions to the common problems and questions, global sales network distribution, global purchasing, news center, product center and human resource center and so on. Only the electronic commerce platform with the complete functions can win more commercial opportunities.

\subsection{Proving the Safe Transaction Environment}

The traditional agricultural product transaction habit, which mainly is the opposite transaction with settling the goods and payment face to face and being afraid of the virtual network has made it difficult to maintain the client group and constrained the expansion of the client range. So the electronic commerce platform providing a safe traction environment is the fundamental guarantee for the success of an electronic commerce platform. For such a concern, it is necessary to establish a uniform, authoritative and nationwide certification center of the agricultural products as quickly as possible, integrating the sources, strengthening the certification to the enterprises and individuals and enhancing the network safety. 


\subsection{Closely Combined with All Chains of Production}

The platform pays too much attention to the sales of finish agricultural products, and ignores the preproduction and mid-production service of agricultural products. Based on the price information and transaction information of agricultural products provided, conduct selection, analysis and treatment of information provided to predict the preproduction price and sales volume and guide the production scale and investment cost for members; provide subsidiary agricultural products for industry information production technology in the mid-production process to minimize the production cost. This mode solves the sales problems(agricultural product marketing or purchase problems of processing enterprises)for producers. Through the above process connect the production and sales to actively promote the online transaction.

\subsection{Properly Promoting Platforms Online}

Properly publicize and promote the websites for electronic commerce platform for agricultural products, to expand visiting volume and win the social concern and recognition. Attention shall be paid to the following items: the platform design shall have agricultural characteristics, excellent safety and interchangeability; release website information on various public media; release advertisement bar in the relevant websites of Internet and set relevant links; send e-mail to potential customers and seek potential trade opportunities; set own position in the search engine to make yourself be found by the potential customers.

The electronic commerce in China has just started. The agricultural electronic commerce faces huge opportunity and serious challenge. There are many problems and difficulties ahead. The construction of electronic commerce platform for agricultural products can only be a successful one when based on the actual situation and further open the market for agricultural products. And the platform can only succeed in the trend of economic globalization through breaking the territories and countries and participating in the international competition.

\section{Acknowledgments}

This work was supported by the Science and Technology Department of Hebei Province. The topic of the research is "New Countryside Construction Integration Strategy of Agriculture E-commerce in Hebei Province".

\section{References}

1. Hua, J.: Research on Current Situation, Problem and Countermeasure of the Electronic Commerce of Agricultural Product in China. Journal of Anhui Agricultural Sciences (19), 124-126 (2006)

2. Zhao, Y., Li, L., Lv, J.: Research and Analysis on Agricultural Electronic Commerce. Rural Economy and Science-Technology 5, 24-25 (2006)

3. Wei, Y., Wu, J., Xiong, Z.: Current Situation, Problem and Countermeasure of the Agricultural Electronic Commerce in China. ACTA Agriculture Jiangxi 5, 214-216 (2006) 